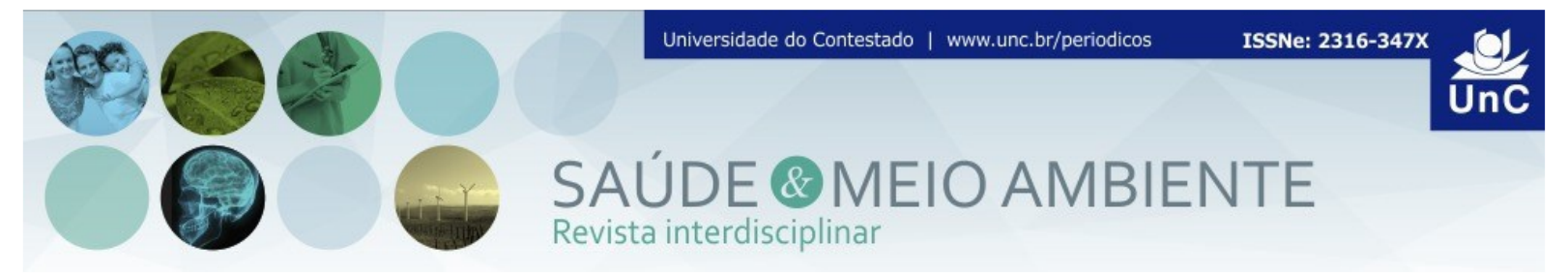

\title{
DETECÇÃO SOROLÓGICA DE ANTICORPOS ANTI-Leishmania infantum chagasi EM CÃES ATENDIDOS EM HOSPITAL VETERINÁRIO ESCOLA
}

\author{
Daniela Pedrassani ${ }^{1}$ \\ Djalmo Gervásio Rodrigues ${ }^{2}$ \\ Rubiana Carvalho dos Santos ${ }^{3}$ \\ Amanda Pedrassani Andrejow 4 \\ Fabiano Borges Figueiredo ${ }^{5}$
}

\section{RESUMO}

A leishmaniose é uma zoonose que atualmente encontra-se entre as seis endemias consideradas prioritárias no mundo. No Brasil, a distribuição geográfica desta doença vem ampliando, tanto na população de cães, quanto na humana. O estado de Santa Catarina era considerado indene para leishmaniose visceral até 2010 quando foram descritos os primeiros casos autóctones em caninos na capital. Com base na recente detecção de casos no Estado, os objetivos deste trabalho foram determinar o percentual de cães soro reagentes na pesquisa de anticorpos antiLeishmania infantum entre os atendidos no hospital veterinário da Universidade do Contestado, em Canoinhas, Santa Catarina e verificar o conhecimento dos tutores destes animais com relação a aspectos de transmissão, de diagnóstico e de profilaxia da leishmaniose visceral canina. Para tal, os animais foram submetidos a um exame físico e coleta de amostra de sangue sem anticoagulante, sendo o soro obtido por centrifugação. A detecção de anticorpos no soro foi pelos testes de ELISA indireto (SNAP Leishmania ${ }^{\circ}$ Idexx) e imunocromatográfico (Dual Plate Platform DPP® Biomanguinhos/Fiocruz). Simultaneamente os tutores respondiam a um questionário para determinar o perfil socioeconômico e o conhecimento sobre leishmaniose visceral. Dentre os 72 cães examinados entre junho a dezembro de 2016 nenhum foi reagente nos testes. Os animais atendidos residiam em diversas cidades da região norte de Santa Catarina, principalmente em Canoinhas e Três Barras e, até no sul do Paraná. Relativo aos tutores, a maioria relatou desconhecer sobre a existência da doença, sobre os meios pelos quais é transmitida e as suas

\footnotetext{
${ }^{1}$ Doutorado Medicina Veterinária Preventiva - UNESP/2009. Mestrado Ciências Veterinárias UFPR/2001. Graduação em Medicina Veterinária - UFPR/1998. Professora do Depto de Medicina Veterinária/UnC Canoinhas. Universidade do Contestado (UnC). Santa Catarina. Brasil. E-mail: daniela@unc.br. ORCID: https://orcid.org/0000-0001-6283-4981

${ }^{2}$ Graduando em Medicina Veterinária. Estagiário do Hospital Veterinário da Universidade do Contestado UnC. Universidade do Contestado (UnC). Canoinhas. Santa Catarina. Brasil. E-mail: djalmogervasio@hotmail.com

${ }_{3}^{3}$ Graduando em Medicina Veterinária. Estagiário do Hospital Veterinário da Universidade do Contestado UnC. Universidade do Contestado (UnC). Canoinhas. Santa Catarina. Brasil. E-mail: rubianacarvalho@hotmail.com

${ }^{4}$ Graduanda em Medicina. Pontifícia Universidade Católica do Paraná. Curitiba. Paraná. Brasil. Email: amanda-pedrassani@hotmail.com

${ }^{5}$ Doutor em Pesquisa Clínica em Doenças Infecciosas Instituto Nacional de Infectologia Evandro Chagas INI FIOCRUZ. Pesquisador em Saúde Pública do Laboratório de Biologia Celular - Instituto Carlos Chagas. Curitiba. Paraná. Brasil. E-mail: fabiano.figueiredo@fiocruz.br
} 
consequências. Conclui-se que embora os animais testados não tenham sido reagentes, é necessária uma maior divulgação desta doença, pois atualmente é comum o trânsito de animais entre regiões, seja pelo comércio ou mudança de seus tutores. A leishmaniose é uma importante zoonose que vem se disseminando a cada dia, principalmente devido às dificuldades inerentes ao controle de seu vetor. Cabe aos médicos veterinários, de acordo com o conceito de saúde única, a busca ativa e precoce de casos e a divulgação de medidas profiláticas e de controle desta zoonose.

Palavras-Chave: Leishmaniose Visceral. Cães. Teste imunocromatográfico. Ensaio imunoenzimático.

\title{
SEROLOGICAL DETECTION OF ANTIBODIES ANTI-Leishmania infantum IN DOGS ATTENDED AT A VETERINARY SCHOOL HOSPITAL
}

\begin{abstract}
Leishmaniasis is a zoonosis that currently ranks among the six endemics considered priority in the world. In Brazil, the geographic distribution of this disease increases every year, in dogs as well as in the human population. The State of Santa Catarina was considered area without previous cases for visceral leishmaniasis until 2010 when the first autochthonous cases were described in canines in the capital of the state. Based on the recent case in the State, the objectives of this study were to determine the percentage of serum sera in anti-Leishmania infantum antibodies among those seen at the University Veterinary Hospital in Canoinhas, Santa Catarina State, Brazil and to verify the owners' knowledge about aspects of transmission, diagnosis and prophylaxis of canine visceral leishmaniasis. The animals were submitted to a physical examination and then a blood sample was collected without anticoagulant, the serum being obtained by centrifugation. Serum antibody detection was done by the Indirect Enzyme-linked immunosorbent assay (SNAP Leishmania ${ }^{\circledR}$ Idexx) and Dual Plate Platform (DPP® Biomanguinhos/Fiocruz) tests. Simultaneously, the owners answered a questionnaire to determine the socioeconomic profile and knowledge about visceral leishmaniasis. Although the veterinary hospital receives animals from several cities in the northern region of Santa Catarina and even southern Paraná, no animal among the 72 examined between June and December 2016 was reagent to the rapid tests. Most of the owners were unaware of the existence of the disease and had no information about the means of transmission and its consequences. It is concluded that although the tested animals are not serum reagents, it is necessary a broader communication of the disease, since at the moment it is common the transit of animals between regions, either by the trade or change of domicile of the owners. Leishmaniasis is an important zoonosis that is spreading every day, mainly because of the difficulties inherent in your vector control. It is the responsibility of veterinarians, according to the concept of unique health, search for cases and to publish information on how to prevent this zoonotic disease.
\end{abstract}

Keywords: Visceral Leishmaniasis. Dogs. Immunochromatographic test. Enzyme immunoassay. 


\section{INTRODUÇÃO}

A Leishmaniose é uma doença zoonótica tropical negligenciada, causada por protozoários parasitos (Kinetoplastidae: Trypanosomatidae) pertencentes ao gênero Leishmania. As leishmanias do complexo Leishmania braziliensis e Leishmania mexicana são os agentes responsáveis pela leishmaniose cutânea. Os agentes etiológicos da leishmaniose visceral são do complexo Leishmania donovani, sendo a Leishmania (L.) donovani o agente etiológico encontrado na África e Ásia; Leishmania (Leishmania) infantum na Ásia, Europa e África e Leishmania infantum chagasi nas Américas (BRASIL, 2014; SILVA; MADEIRA; FIGUEIREDO, 2015).

Apesar da discordância entre pesquisadores, semelhanças estruturais verificadas por meio de estudos moleculares sugerem que a $L$. chagasi e a $L$. infantum sejam a mesma espécie, permitindo a denominação $L$. infantum para o agente etiológico desta enfermidade também nas Américas (MAURICIO et al., 2000; SHAW et al., 2006; SILVA; MADEIRA; FIGUEIREDO, 2015).

No Brasil, sua transmissão ocorre por meio da picada das fêmeas dos vetores biológicos da espécie Lutzomyia longipalpis e mais recentemente descrito, também pelos da espécie L. cruzi, infectados pela Leishmania infantum chagasi (BRASIL, 2014; SARAIVA et al., 2009). Nas áreas urbanas, o cão doméstico é sua principal fonte de infecção (BRASIL, 2014) e a enzootia canina tem precedido a ocorrência de casos humanos (ALVES; BEVILACQUA, 2004; BRASIL, 2014). Sua importância como reservatório está no contato frequente entre homens e cães e no fato desses animais poderem apresentar infecção assintomática, apesar do alto grau de parasitismo em pele e vísceras (MARZOCHI et al., 2009).

O estado de Santa Catarina era considerado indene para leishmaniose visceral, até 2010, quando foram descritos os primeiros casos autóctones de leishmaniose visceral canina, na capital Florianópolis (FIGUEIREDO et al., 2012). Correa e colaboradores (2011) realizaram em 2010, análise de 102 amostras de soro de cães de Canto dos Araçás, Florianópolis, SC, por RIFI e ELISA, com objetivo de verificar a soro prevalência de leishmaniose visceral canina. Dessas, $6,86 \%$ foram reagentes e os autores concluíram que na área, o cão é o principal reservatório, com possibilidade de transmissão, existindo a necessidade de se manter vigilância sorológica em cães e estudos entomológicos para determinar a identidade do transmissor, na epidemiologia local. Posteriormente, Pacheco et al. (2013) detectaram 5,3\% (25/491) de cães domiciliados no município de Florianópolis, Santa Catarina como reagentes para Leishmania sp. Já Steindel et al. (2013) relataram o primeiro surto autóctone de leishmaniose visceral canina (LCV) em Santa Catarina, também no município de Florianópolis.

Quando cães são infectados, apresentam sinais clínicos inespecíficos como febre, linfadenopatia, anemia, caquexia progressiva, epistaxe (ALMEIDA et al., 2005; BRASIL, 2014; SESA, 2018) e alterações dermatológicas como dermatite descamativa, ulcerativa e onicogrifose (FEITOSA, 2000, SESA, 2018). Apesar do acometimento geral de diversos sistemas, a principal causa de morte nos cães 
parasitados é a insuficiência renal (FEITOSA, 2000). Devido à variedade e inespecificidade dos sinais clínicos da doença, o diagnóstico clínico da LVC torna-se difícil de ser realizado, salientando a necessidade da utilização de métodos sorológicos e parasitológicos para sua confirmação (BRASIL, 2014; FEITOSA et al., 2000). A LVC pode ser clínica e laboratorialmente confundida com uma ampla gama de doenças caninas e o conhecimento de suas manifestações clínicas e de procedimentos laboratoriais específicos e sensíveis para esse diagnóstico, são de grande importância para uma rápida confirmação e notificação do caso, contribuindo assim diretamente para o controle do foco (CAMPOS et al., 2013).

Os exames sorológicos recomendados pelo Ministério da Saúde, para diagnóstico de LVC até 2011 eram o ELISA indireto, como teste de triagem, e o de IFI, como confirmatório. A partir de 2012, o Ministério da Saúde emitiu uma nota técnica orientando a utilização de um teste rápido imunocromatográfico (DPP) como triagem e do ELISA como teste confirmatório da doença (BRASIL, 2011).

O teste imunocromatográfico DPP® (Bio-Manguinhos $®$ ) é um teste qualitativo rápido, eleito como exame de triagem, para detecção de anticorpos anti-Leishmania. Este imunoensaio de dupla plataforma possui Proteína A conjugada ao ouro coloidal, adsorvidos em membrana de nitrocelulose, para emitir cor e, utiliza a fusão de duas proteínas recombinantes, rK39 e rK26, como antígeno. A rK39 é o produto de um gene clonado a partir de $L$. infantum e que contém uma repetição de 39 aminoácidos conservados entre as espécies de Leishmania donovani e L. infantum. A rK39 e a rK26 conferem grande sensibilidade quando utilizadas em diagnóstico sorológico, sendo capazes de reconhecer anticorpos anti-Leishmania infantum. $\mathrm{O}$ teste pode ser realizado com sangue, soro ou plasma e obtém-se o resultado em 15 minutos (LAURENTI et al., 2014).

$\mathrm{Na}$ tentativa de implementar medidas de controle da doença, o programa de Vigilância e Controle da Leishmaniose Visceral no Brasil classifica os municípios em silenciosos, em investigação e com transmissão (BRASIL, 2014). Os silenciosos são aqueles que não apresentam casos autóctones em seres humanos ou animais. Estes podem ainda ser classificados em receptivos, quando da presença do vetor $\mathrm{e}$ vulneráveis na dependência da proximidade a eixos viários que permitam maior migração. Os municípios em investigação são municípios silenciosos com notificação de caso humano ou canino clinicamente suspeito, cão parasitologicamente positivo ou cão soro reagente aguardando conclusão de outros itens de investigação epidemiológica. Por último, os municípios com transmissão podem ser aqueles somente com transmissão canina, ou aqueles com transmissão humana. Diante da classificação do município, são recomendadas ações de vigilância vetorial tais como levantamento entomológico, e de vigilância do reservatório, como inquérito canino (BRASIL, 2014).

É importante que a vigilância entomológica e epidemiológica voltadas para LVC sejam implantadas e implementadas nas áreas indenes, com intuito de detectar a presença do vetor e/ou a enzootia canina antes da instalação do ciclo antropozoonótico, permitindo adotar ações que visem impedir a ocorrência da doença em humanos, ou até mesmo preparar os serviços de saúde e a população 
para o enfrentamento do problema (FIGUEIREDO et al., 2012; SILVA; MADEIRA; FIGUEIREDO, 2015).

Tem sido relatado que o perfil socioeconômico e o conhecimento da população são importantes ferramentas para a prevenção e controle da leishmaniose (BORASCHI et al., 2008).

Em estudo realizado junto à população ribeirinha da cidade de Mossoró, Rio Grande do Norte, Costa et al. (2014) observaram que 68\% dos entrevistados (19/71) não possuíam qualquer conhecimento acerca da transmissão da LV, possuindo o dobro de risco para positividade canina ao agente em relação àqueles que possuíam tal informação. De forma geral, todos os programas de prevenção e controle de doenças transmissíveis incluem medidas educativas abrangendo a população-alvo. Os projetos educativos em saúde diminuem a problemática da escassez de recursos e a atual falta de infraestrutura dos serviços de saúde, especialmente no que concerne ao diagnóstico precoce, tanto na população humana quanto animal, e no tratamento de casos humanos de LV, que tornam as medidas de controle pouco factíveis (SESA, 2018). Diante da importância da disseminação de informações básicas para a população sobre a leishmaniose visceral, estudos relacionados a este tipo de intervenção passaram a contribuir, consideravelmente, para a elaboração e aprimoramento das medidas preventivas e, portanto, estes são relevantes para a saúde pública (BORGES et al., 2008).

Deste modo, este trabalho teve os objetivos de determinar o percentual de soro reagentes, em pesquisa de anticorpos anti-Leishmania infantum, dentre os cães atendidos no hospital veterinário da Universidade do Contestado, em Canoinhas/SC e verificar o conhecimento dos tutores destes animais com relação a aspectos de transmissão, de diagnóstico e de profilaxia da leishmaniose visceral.

\section{MATERIAL E MÉTODOS}

Este projeto foi aprovado pela Comissão de Ética do Uso e Experimentação de animais (CEUA) (parecer $n^{\circ}$ 01/16) e pelo comitê de Ética em Pesquisa (CEP) (parecer $\left.n^{\circ} 1.475 .210\right)$, da Universidade do Contestado (UnC).

DEFINIÇÃO DA AMOSTRA: O " $n$ " amostral foi definido pela fórmula: $n=$ $\left[\operatorname{EDFF}^{*} \mathrm{~Np}(1-\mathrm{p})\right] /\left[\left(\mathrm{d} 2 / \mathrm{Z21}-\alpha / 2^{*}(\mathrm{~N}-1)+\mathrm{p}^{*}(1-\mathrm{p})\right]\right.$. Levando-se em consideração um atendimento anual de 1.000 cães no Hospital Veterinário da UnC, uma frequência antecipada do fator de 5,3\%, um erro amostral de 5\% e um intervalo de confiança de $95 \%$, com estes elementos, para um período de seis meses (junho até dezembro) a amostra foi definida em 72 cães. 
AMOSTRAS DE SANGUE: as amostras sanguíneas foram coletadas após o consentimento esclarecido dos tutores e conforme a demanda de atendimento do Hospital Veterinário da UnC, localizado em Canoinhas-SC e que atende cães de Canoinhas e de outros municípios próximos.

Após exame físico, amostras de $3 \mathrm{~mL}$ de sangue foram coletadas por punção da veia jugular externa ou cefálica em tubos sem anticoagulante e a seguir centrifugadas a 3.000 RPM por 15 minutos, sendo o soro obtido armazenado a $18^{\circ} \mathrm{C}$ até a realização das análises.

DETECÇÃO DE ANTICORPOS ANTI-LEISHMANIA INFANTUM: a pesquisa de anticorpos foi realizada pelas técnicas de imunocromatografia e ensaio imunoenzimático indireto por meio de kits comerciais específicos para a espécie canina e realizados conforme especificações dos fabricantes.

Brevemente, para $\circ$ teste rápido imunocromatográfico (DPP® Biomanguinhos/Fiocruz) para detecção de anticorpos anti-Leishmania infantum a lanceta coletora foi colocada no microtubo com o soro, permitindo a retirada de $5 \mu \mathrm{L}$ de amostra, que foi aplicada no poço \#1 (amostra + tampão), seguida de duas gotas de tampão. Após cinco minutos da aplicação foram adicionadas quatro gotas de tampão no poço \#2 (tampão). As leituras foram realizadas depois de 15 minutos e, foram considerados reagentes os animais onde no teste apareceram linhas na parte denominada controle $(C)$ e na parte denominada teste $(T)$ e não reagentes aqueles nos quais na leitura do exame apenas apareceu linha na parte denominada controle.

Para o teste SNAP® LEISHMANIA para detecção de anticorpos de Leishmania donovani e $L$. infantum, as amostras de soro foram retiradas com pipeta e duas gotas do soro teste foram colocadas em um microtubo, ao qual foram adicionadas seis gotas de conjugado, homogeneizando em seguida. Com o dispositivo SNAP posicionado em uma superfície plana colocou-se o conteúdo do microtubo na cavidade da amostra. Em seguida o dispositivo foi ativado e a leitura realizada depois de seis minutos. Para determinar o resultado do teste leu-se os três pontos de reação na janela do resultado: o ponto de controle negativo, o de controle positivo e o da amostra teste. Foram consideradas reagentes as amostras onde houve aparecimento de cor no local definido para o controle positivo do teste e no local definido para resultado da amostra teste e, consideradas não reagentes, aquelas amostras nas quais houve aparecimento de cor apenas no local definido para o controle positivo do teste.

QUESTIONÁRIO: um questionário, com 18 perguntas relativas ao animal, ao tutor e a leishmaniose, foi aplicado aos tutores durante a consulta veterinária. $\mathrm{O}$ pesquisador explicava sobre a importância do projeto e esclarecia que a participação era voluntária, com a assinatura de um termo de consentimento livre e esclarecido. 
ANÁLISE DOS DADOS DOS QUESTIONÁRIOS: Os dados obtidos com os questionários foram tabulados e processados em planilhas eletrônicas e em gráficos elaborados no programa Office Excel da Microsoft@. Em seguida, os resultados foram interpretados mediante inclusão dos valores percentuais e análise qualitativa.

\section{RESULTADOS E DISCUSSÃO}

Os animais amostrados eram provenientes de vários municípios do Planalto Norte Catarinense e também do sul do Paraná, principalmente de Canoinhas, SC (76\%), que é o município onde está localizado o Hospital Veterinário da Universidade do Contestado (gráfico 1).

Gráfico 1 - Município de procedência dos cães amostrados $(n=72)$, durante atendimento clínico no hospital veterinário da UnC, para realização de testes sorológicos de pesquisa de anticorpos antiLeishmania infantum, entre junho a dezembro de 2016 em Canoinhas, SC.

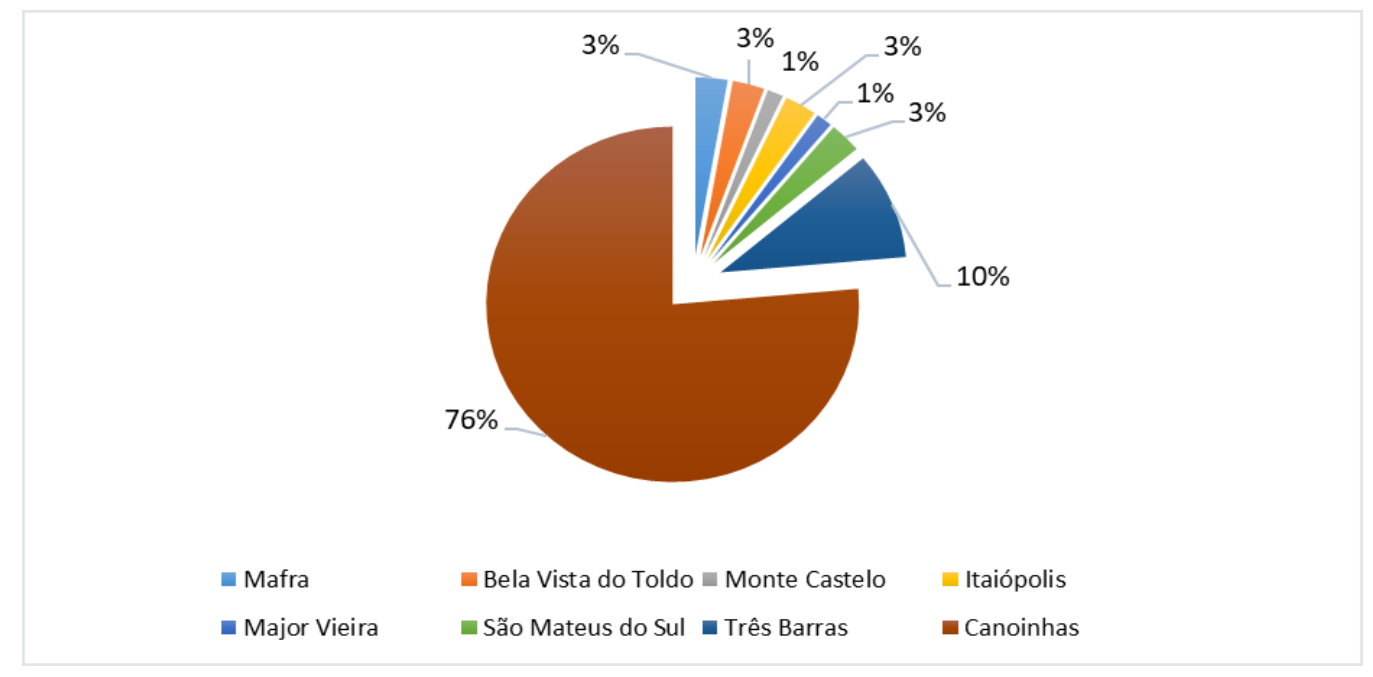

Fonte: dados da pesquisa.

Das 72 amostras coletadas dos animais, 49\% eram provenientes de machos (Tabela 1), 53\% não eram castrados e $75 \%$ eram de animais mantidos como cão de companhia. A maioria dos animais $(78 \%)$ era sem raça definida e $22 \%$ eram de raças como Boxer, Pinscher, American Pit Bull Terrier, Labrador Retriever, Poodle e Galgo Espanhol (Tabela 1). 
Detecção sorológica de anticorpos anti-Leishmania infantum chagasi em cães atendidos em hospital veterinário escola

Tabela 1 - Características de sexo e raça dos cães $(n=72)$ atendidos no hospital veterinário da UnC, para realização de testes sorológicos de pesquisa de anticorpos anti-Leishmania infantum, entre junho a dezembro de 2016 em Canoinhas, SC.

\begin{tabular}{|c|c|c|}
\hline & Característica & Número de animais \\
\hline \multirow[t]{2}{*}{ Sexo } & Fêmea & $37(51 \%)$ \\
\hline & Macho & $35(49 \%)$ \\
\hline \multirow{7}{*}{ Raça } & Sem definição racial & $56(78 \%)$ \\
\hline & Labrador & $04(5,5 \%)$ \\
\hline & Boxer & $04(5,5 \%)$ \\
\hline & Pinscher & $03(4 \%)$ \\
\hline & Pitbull & $02(3 \%)$ \\
\hline & Poodle & $03(4 \%)$ \\
\hline & Total & 72 animais \\
\hline
\end{tabular}

Fonte: Dados da pesquisa.

A idade dos animais variou desde animais com idade inferior a um ano até 13 anos de idade, no entanto o número de tutores que não souberam informar a idade dos seus animais foi de $27,8 \%$ (Gráfico 2).

Gráfico 2 - Idade dos cães amostrados $(n=72)$, durante atendimento clínico no hospital veterinário da UnC, para realização de testes sorológicos de pesquisa de anticorpos anti-Leishmania infantum, entre junho a dezembro de 2016 em Canoinhas, SC.

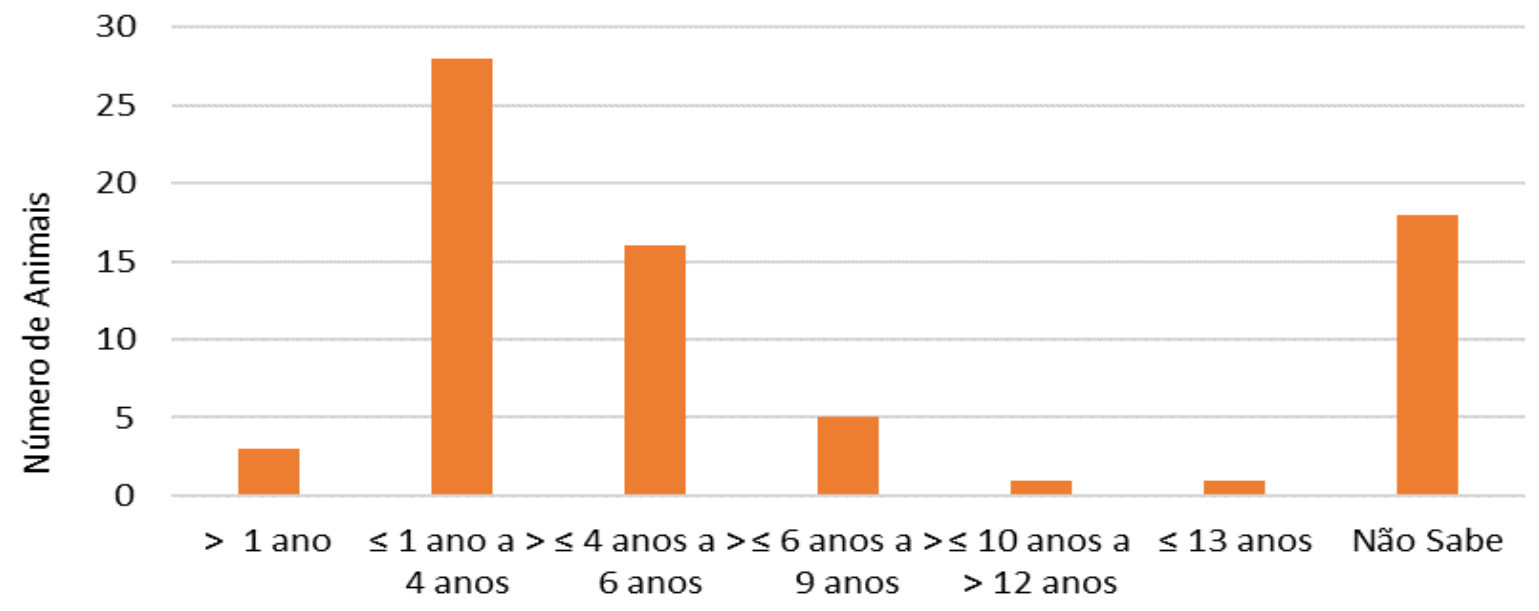

Fonte: dados da pesquisa

Desde os primeiros relatos de casos autóctones de leishmaniose visceral canina (CORREA et al., 2011; FIGUEIREDO et al., 2012; PACHECO et al., 2013; STEINDEL et al., 2013) e em seguida de LV em humanos no Estado de Santa Catarina (SMS, 2017), a doença vem se constituindo em importante preocupação para a saúde pública no estado. Neste estudo, tanto pelo Teste imunoenzimático SNAP® LEISHMANIA IDEXX quanto pelo Teste imunocromatográfico DPP®, todos os animais testados foram não reagentes na pesquisa de anticorpos anti- $L$. Infantum. Estes resultados do inquérito sorológico eram esperados, os animais são 
procedentes, em sua maioria do município de Canoinhas, mas também de outros municípios do Planalto Norte Catarinense e também do sul da Paraná e estas áreas são consideradas como áreas indenes para a leishmaniose visceral canina.

Embora nenhum animal foi reagente na pesquisa de anticorpos, o fato de ser uma cidade com fluxo migratório de universitários de outros municípios e estados (com o animal de estimação em muitas das vezes) e atendimento/ internamento de cães de outros municípios no Hospital veterinário universitário, são fatores que podem contribuir para a introdução de um animal parasitado em Canoinhas. Conforme Carvalho (2007) um aspecto importante na epidemiologia da LVC é o fluxo de cães entre municípios, contribuindo para a introdução desta zoonose em locais onde não existiam relatos de sua ocorrência, mas que apresentavam o vetor no ambiente. Em seu estudo, em Botucatu, SP 33,3\% das famílias participantes do estudo informaram que os animais eram oriundos de outros municípios, muitos deles endêmicos para a LVC e, deste total, $12,8 \%$ dos cães foram reagentes na sorologia para LVC.

A idade média dos tutores que responderam o questionário foi de 35 anos, variando de 18 anos até 61 anos. Cerca de $55,5 \%$ da população estudada encontrava-se estruturada em núcleos familiares com renda igual ou inferior a 3 salários-mínimos, e com $69,4 \%$ com escolaridade até no máximo o ensino médio, sugerindo um baixo nível socioeconômico dos entrevistados.

Sobre o conhecimento relacionado à $L V, 74 \%$ dos tutores alegaram não ter conhecimento sobre a doença e, apenas $26 \%$ afirmaram conhecer por terem lido sobre o assunto ou por meios de noticiários de televisão ou em redes sociais; $76,38 \%$ não sabia se era uma doença transmissível e $81,94 \%$ dos tutores alegaram desconhecer o modo de transmissão. Sobre a doença acometer ou não o ser humano, 73,61\% alegaram não saber e 4,17\% afirmaram não ser zoonótica (Tabela 2).

De acordo com os tutores nenhum dos cães e em nenhuma faixa etária recebeu vacina para prevenir a leishmaniose e em relação a vacinação profilática de raiva e óctupla, obteve-se que $29 \%$ dos cães não são vacinados com nenhuma vacina e $48 \%$ dos cães receberam estas vacinas.

É de se esperar que o grau de conhecimento sobre a leishmaniose visceral, e a própria situação epidemiológica da mesma, devam influenciar o nível de informações adquiridas e acumuladas pelos entrevistados. $\mathrm{O}$ fato de Canoinhas e cidades vizinhas serem consideradas como áreas indenes para LVC devem ter contribuído para o baixo grau de conhecimento referentes a doença, aos sinais clínicos nos cães e a possibilidades de tratamento e vacinação observadas neste estudo.

Paulan et al. (2016) em estudo realizado em Ilha Solteira, SP, área de ocorrência de LVC, observaram que $77 \%$ das famílias declararam saber o que é a leishmaniose. Apesar disso, 46,15\% dessas famílias eram tutoras de cães com LVC e, segundo os autores, apesar do conhecimento acerca da doença, medidas profiláticas não estão sendo realizadas adequadamente. Entretanto, conforme 
Boraschi et al. (2008) quando ao menos um método de prevenção é adotado pela população, observa-se uma correlação significativa em relação a diminuição da positividade em cães.

Sobre os sinais clínicos em cães com leishmaniose visceral $91,67 \%$ dos tutores alegaram não ter conhecimento e $86,11 \%$ desconhecem se esta doença possui tratamento. Adicionalmente, $87,5 \%$ dos tutores não conhecia a vacina contra a leishmaniose.

Já Paulan et al. (2016) verificaram que $84,62 \%$ das famílias, ou seja, a maioria, demonstraram capacidade de reconhecer os sinais clínicos da doença no seu cão e sobre o tratamento, $56,41 \%$ das famílias disseram não existir tratamento para o cão. Percebe-se que o conhecimento sobre o tratamento em cães, mesmo nas áreas de ocorrência de LVC é um assunto que merece ser mais amplamente discutido e divulgado.

O uso de produtos repelentes profilaticamente nos cães não é praticado por $78 \%$ dos tutores. Este comportamento expõe os cães a inúmeras doenças ocasionados por artrópodes e também aquelas transmitidas por vetores artrópodes, dentre as quais se inclui a Leishmaniose.

A grande expansão das doenças infecciosas e parasitárias no Brasil, está, em grande parcela, relacionada a fatores como falta de informação e de ações preventivas (CASTRO et al., 2016).

Tabela 2 - Questões sobre Leishmaniose visceral coletadas com os tutores de 72 cães atendidos no hospital veterinário da UnC, Canoinhas-SC entre junho a dezembro de 2016.

\begin{tabular}{c|ccc}
\hline VARIÁVEL & Resposta & Total & $(\%)$ \\
\hline Ouviu falar em Calazar/Leishmaniose Visceral & Sim & 19 & 26 \\
& Não & 53 & 74 \\
& Não sabia & - & - \\
\hline Sabe se é transmissível & Não respondeu & - & - \\
\hline Sabe como é a transmissão & Sim & 15 & 20,83 \\
& Não & 7 & 9,72 \\
& Não sabia & 48 & 66,66 \\
\hline & Não respondeu & 2 & 2,79 \\
\hline Conhece sobre sinais clínicos no cão & Sim & 10 & 13,90 \\
& Não & 59 & 81,94 \\
& Não sabia & - & - \\
\hline & Não respondeu & 3 & 4,16 \\
\hline & Sim & 6 & 8,33 \\
& Não & 66 & 91,67 \\
\hline & Não sabia & - & - \\
\hline & Não respondeu & - & - \\
\hline & Sim & 3 & 4,17 \\
\hline & Não & 7 & 9,72
\end{tabular}




\begin{tabular}{c|ccc} 
& Não sabia & 62 & 86,11 \\
\hline Existe vacina & Não respondeu & - & - \\
\hline & Sim & 3 & 4,17 \\
& Não & 6 & 8,33 \\
& Não sabia & 63 & 87,50 \\
\hline Esta doença pode acometer o ser humano & Não respondeu & - & - \\
\hline & Sim & 16 & 22,22 \\
& Não & 3 & 4,17 \\
& Não sabia & 53 & 73,61 \\
\hline & Não respondeu & - & - \\
\hline
\end{tabular}

Fonte: dados da pesquisa

Desta forma, o presente estudo, revelou que os tutores dos animais amostrados possuem pouco conhecimento sobre a doença, indicando a necessidade de implementação de medidas de educação em saúde.

\section{CONCLUSÃO}

A leishmaniose visceral canina não é uma afecção diagnosticada em cães atendidos no hospital veterinário da UnC, pela avaliação dos resultados dos exames sorológicos.

O conhecimento sobre a leishmaniose visceral canina dos tutores participantes é limitado. Sugere-se a continuidade da vigilância com triagem por testes rápidos em cães e um trabalho mais intenso de educação em saúde sobre leishmaniose visceral canina, para facilitar a elaboração de estratégias futuras para atuação local, caso a doença seja introduzida no município onde o Hospital Veterinário da UnC está localizado.

\section{REFERÊNCIAS}

Alves W. A., Bevilacqua P. D. Reflexões sobre a qualidade do diagnóstico da leishmaniose visceral canina em inquéritos epidemiológicos: o caso da epidemia de Belo Horizonte, Minas Gerais, Brasil, 1993-1997. Cadernos de Saúde Pública, Rio de Janeiro, 20(1); 2004. Disponível em: <http://www.scielo.br/scielo.php?pid=S0102311X2004000100043\&script=sci_abstract\&tlng=pt>. Acesso em: fev. 2016. 
Detecção sorológica de anticorpos anti-Leishmania infantum chagasi em cães atendidos em hospital veterinário escola

Almeida M. A. et al. Clinical and serological aspects of visceral leishmaniasis in northeast Brazilian dogs naturally infected with Leishmania chagasi. Veterinary Parasitology, 127(3-4): 227-232; 2005.

Brasil. Ministério da Saúde. Secretaria de Vigilância em Saúde. Departamento de Vigilância Epidemiológica. Manual de vigilância e controle da leishmaniose visceral. 1. ed. Brasília: Ministério da Saúde; 2014. Disponível em: $<$ http://bvsms.saude.gov.br/bvs/publicacoes/manual vigilancia controle leishmanios e visceral 1edicao.pdf> Acesso em: abr. 2015.

Departamento de Vigilância das Doenças transmissíveis. Nota Técnica conjunta $n^{\circ}$ 1/2011 CGDT-CGLAB/DEVIT/SVS/MS, 2011. Disponível em: <http://www.sgc.goias.gov.br/upload/arquivos/2012-05/nota-tecnica-no.-1$2011 \mathrm{cglab}$ cgdt1 Ivc.pdf>. Acesso em : fev. 2016.

Boraschi C. S. S., Perri S. H. V., Nunes C. M. Leishmaniose visceral: o que a população de três lagoas sabe sobre esta enfermidade? Veterinária e Zootecnia, 15(3):478-485; 2008.

Borges B. K. A. et al. Avaliação do nível de conhecimento e de atitudes preventivas da população sobre a leishmaniose visceral em Belo Horizonte, Minas Gerais, Brasil. Cadernos de Saúde Pública, 24(4): 777-784; 2008.

Campos M. P. et al. First autochthonous case of canine visceral leishmaniasis in Volta Redonda, Rio de Janeiro, Brazil. Revista Brasileira de Parasitologia Veterinária, Jaboticabal, 22(3): 424-426; 2013. Disponível em: <http://www.scielo.br/pdf/rbpv/v22n3/0103-846X-rbpv-22-03-424.pdf Acesso em: mar. 2017.

Carvalho J. L. B. Leishmaniose visceral canina: busca ativa de casos e estudo sobre o conhecimento da doença em proprietários de cães na área urbana de Botucatu. 2007. 65 f. Dissertação (Mestrado em Medicina Veterinária) - Faculdade de Medicina Veterinária e Zootecnia, Universidade Estadual Paulista, Botucatu; 2007.

Castro J. M., Rodrigues S. M., Silva S. T. P., Lacerda Costa F. C., Rodrigues A. C. D. C. P., Vieira L. D. F. Borja-Cabrera G. P. Conhecimento, percepções de indivíduos em relação à leishmaniose visceral humana como novas ferramentas de controle. Ensaios e Ciência: C. Biológicas, Agrárias e da Saúde, 20(2): 93-103; 2016.

Corrêa G. L. B. et al. Inquérito canino censitário de leishmaniose visceral no município de Florianópolis, em 2010; 2011. Disponível em: http://www.pmf.sc.gov.br/arquivos/arquivos/PDF/16 $11 \quad 2011 \quad$ 10.24.22.2871ae70a3 883368f5fb35793a3b4b00.PDF Acesso em: 16 jul. 2014.

Costa, K.F.L.; Amora, S.S.A.; Couto, C.F.A.; Souza, C.S.F.; Silva, L.F.; d'Escoffier, L.N. et al. Awareness of visceral leishmaniasis and its relationship to canine infection in riverside endemic areas of Northeastern Brazil. Revista da Sociedade Brasileira de Medicina Tropical, 47(5):607-612; 2014. 
Feitosa M.M. et al. Aspectos clínicos de cães com leishmaniose visceral no município de Araçatuba, São Paulo (Brasil). Clínica Veterinária, 28:36-44; 2000.

Figueiredo F. B. et al. Leishmaniose Visceral Canina: dois casos autóctones no município de Florianópolis, estado de Santa Catarina. Acta Scientiae Veterinariae, 40(1):1026; 2012.

Florianópolis. Prefeitura Municipa. Secretaria Municipal de Saúde. Alerta Epidemiológico. 13 dez. 2017. Disponível em:

<http://www.pmf.sc.gov.br/arquivos/arquivos/pdf/14_12_2017_14.52.54.2be8663cb5 c0d895f08fe96e401a304e.pdf>. Acesso em: 05 mar. 2019.

Laurenti M. D. et al. Comparative evaluation of the DPP® CVL rapid test for canine serodiagnosis in area of visceral leishmaniasis. Veterinary parasitology, 205(3-4): 444-450; 2014

Marzochi M.C.A. et al. Visceral leishmaniasis in Rio de Janeiro, Brazil: ecoepidemiological aspects and control. Revista da Sociedade Brasileira de Medicina Tropical, 42(5): 570-580; 2009.

Mauricio I.L., Stothard J.R., Miles M.A. The strange case of Leishmania chagasi. Parasitology today, 16(5):188-189; 2000.

Pacheco, A. D. et al. Leishmania sp. infection in dogs from Florianópolis, Santa Catarina, SC, Brazil. Brazilian Journal of Veterinary Research and Animal Science, São Paulo, 50(3): 220-225; 2013. Disponível em: https://www.researchgate.net/publication/288400142 Leishmania sp Infection in d ogs from Florianopolis Santa Catarina SC Brazil/download Acesso em: mar. 2016.

Paulan S. C., Silva D. T., Souza Lins A. G., Lima F. L., Tenório M. S., Tasca K. I. et al. O conhecimento sobre leishmaniose visceral: Suficiente para controle e prevenção? Revista Ciência em Extensão, 12(2):47-60; 2016.

Saraiva L. et al. Natural infection of Lutzomyia neivai and Lutzomyia sallesi (Diptera: Psychodidae) by Leishmania infantum chagasi in Brazil. Journal of Medical Entomology, 46(5):1159-1163; 2009.

Santa Catarina. Secretaria de Estado Saúde SESA/SC. Guia de orientação para a vigilância da leishmaniose visceral canina (LVC). Florianópolis: SESA-SC; 2018.

Silva D. A., Madeira M. F., Figueiredo F. B. Brief communication geographical expansion of canine visceral leishmaniasis in Rio de Janeiro State, Brazil. Revista do Instituto de Medicina Tropical de São Paulo, 57(5):435-438; Sept.-Oct. 2015

Shaw J. J. Further thoughts on the use of the name Leishmania (Leishmania) infantum chagasi for the aetiological agent of American visceral leishmaniasis. Memórias do Instituto Oswaldo Cruz. 101: 577-579; 2006. 
Steindel M. et al. Outbreak of autochthonous canine visceral leishmaniasis in Santa Catarina, Brazil. Pesquisa Veterinária Brasileira, 33; 2013. Disponível em:

http://www.scielo.br/pdf/pvb/v33n4/v33n4a13.pdf Acesso em: fev. 2016

Artigo recebido em: 24/05/2019

Artigo aprovado em: 05/07/2019

Artigo publicado em: 12/08/2019 